Electronic Physician (ISSN: 2008-5842)

http://www.ephysician.ir

August 2016, Volume: 8, Issue: 8, Pages: 2752-2758, DOI: http://dx.doi.org/10.19082/2752

\title{
Effect of aqueous and ethanolic extracts of Lippia citriodora on candida albicans
}

\author{
Maryam Ghasempour ${ }^{1}$, Saeid Mahdavi Omran², Ali Akbar Moghadamnia ${ }^{3}$, Faranak Shafiee ${ }^{4}$
}

${ }^{1}$ DDS, MS, Faculty of Dentistry, Babol University of Medical Sciences, Babol, Iran

${ }^{2}$ Ph.D., Cellular and Molecular Biology Research Center, Department of Medical Parasitology and Mycology, Babol University of Medical Sciences, Babol, Iran

${ }^{3}$ Ph.D., Department of Pharmacology and Toxicology, Faculty of Medicine, Babol University of Medical Sciences, Babol, Iran

${ }^{4}$ DDS, Postgraduate Student, Faculty of Dentistry, Babol University of Medical Sciences, Babol, Iran

\section{Type of article: Original}

\begin{abstract}
Introduction: Because of resistance and side effects to common antifungal drugs activity, the research on herbal substances with antifungal activity is frequent. Lemon verbena (Lippia citriodora) is a member of Verbenaceae family. The aim of this study was to determine the anti-candida activities of the ethanolic and aqueous extracts of the lemon verbena leaves and compare them with nystatin and fluconazole.

Methods: In this 2015 study, 15 clinical isolates and standard strain of candida albicans PTCC 5027 were used, and the inhibitory effects of the ethanolic and aqueous extracts, Nystatin and Fluconazole, were evaluated using disk and well diffusion methods. Also, the minimal inhibitory concentration (MIC) was determined. Five concentrations of aqueous and ethanolic extracts (156-2500 $\mu \mathrm{g} / \mathrm{ml})$, Nystatin $(8-128 \mu \mathrm{g} / \mathrm{ml})$ and Fluconazole (4$64 \mu \mathrm{g} / \mathrm{ml}$ ) were used in disk and well diffusion methods, and nine concentrations of aqueous and ethanolic extracts $(19-5000 \mu \mathrm{g} / \mathrm{ml})$, Nystatin $(0.5-128 \mu \mathrm{g} / \mathrm{ml})$, and Fluconazole $(0.25-64 \mu \mathrm{g} / \mathrm{ml})$ were applied for MIC. Data were analyzed using Tukey's post-hoc and one-way ANOVA tests. The significant level was considered $\mathrm{p}<0.05$ in the current study.

Results: In the well and disk diffusion techniques, limited growth inhibition halos were produced around some clinical isolates at different concentrations of ethanolic extract; however, no growth inhibitory halo was observed with any concentrations of the aqueous extract. The MIC values of ethanolic extract, aqueous extract, Nystatin and Fluconazole for clinical isolated and standard strain were $833 \pm 78.5$ and $625 \mu \mathrm{g} / \mathrm{ml} ; 4156 \pm 67.4$ and 2500 $\mu \mathrm{g} / \mathrm{ml} ; 10.13 \pm 1.91$ and $4 \mu \mathrm{g} / \mathrm{ml}$; and $1.97 \pm 0.25$ and $1 \mu \mathrm{g} / \mathrm{ml}$, respectively.

Conclusion: The results showed that the ethanolic extract was stronger than the aqueous extract of this plant, which can be used as an alternative for drugs. It is recommended that the ethanolic extract of this plant be investigated in vivo for better evaluation of its efficacy and properties.

Keywords: Anti-Candida albicans activity, Lippia citriodora, Ethanolic and Aqeoues extracts, Nystatin, Fluconazole
\end{abstract}

\section{Introduction}

Oral candidiasis is one of the most common opportunistic infections with varying clinical manifestations that affect the oral cavity. Based on previous studies, Candida albicans is the most common etiologic agent for this condition $(1,2)$. Research has shown a significant correlation between Candida colonies in children and early carious lesions during childhood $(3,4)$. Polyenes (nystatin) and azoles (fluconazole) are the most commonly-used local agents for the treatment of candidiasis; however, due to the presence of resistant species of Candida, toxicity, and insufficient bioavailability, only a small number of these agents are effective therapeutically (5). In recent decades, plant derivatives have attracted a lot of attention (6). One of these plants with excellent therapeutic properties is Lippia citriodora from the Verbena family. The plant is indigenous to North America; however, it has been planted in some

\section{Corresponding author:}

Dr. Faranak Shafiee, Faculty of Dentistry, Babol University of Medical Sciences, Babol, Iran. Tel: +98.9183733349, Email: faranakshafiee@gmail.com

Received: November 21, 2015, Accepted: February 28, 2016, Published: August 2016

iThenticate screening: February 28, 2016, English editing: May 17, 2016, Quality control: August 02, 2016

(C) 2016 The Authors. This is an open access article under the terms of the Creative Commons Attribution-NonCommercialNoDerivs License, which permits use and distribution in any medium, provided the original work is properly cited, the use is non-commercial and no modifications or adaptations are made. 
European countries and in Iran in regions with moderate weather conditions (northern areas) under greenhouse conditions due to its beneficial properties (7). The leaves of this plant have aromatic constituents, which are used to prepare traditional tea. L. citriodora has been listed as one of the safe plants and use of its alcoholic and traditional tea forms has been considered safe (8). Citral (geranial, neral), geraniol, lemonene, and cineol are the main ingredients of the extract of L. citriodora (9). This plant is used in traditional medicine for the treatment of asthma, spasms, colds, colic, diarrhea, malabsorption, and anxiety (10). Evaluation of the biological activity and ingredients isolated from the extract and leaf extract of L. citriodora showed its anti-oxidative, anti-microbial, antiinflammatory, and anti-fungal activities and analgesic effects as a result of its phenolic acid, flavonoid, and terpenoid compounds. The essential oils of $L$. citriodora decrease cellular lysis due to oxidative stresses, and they are a good candidate for conditions leading to neuronal degradation $(8,10-13)$. The aim of the present study was to determine the inhibitory effect of the aqueous and ethanolic extracts of L. citriodora leaves on Candida albicans isolated from the dorsum of the tongue of patients and the standard strain in culture media.

\section{Material and Methods}

\subsection{Study design and setting}

In this in vitro study, we used the standard strain of Candida albicans (PTCC 5027) procured from the Industrial Microorganism Collection Center of Iran and 15 C. albicans samples isolated from the dorsum of the tongue of 412-year-old children who were referred to the Department of Pediatric Dentistry of Babol University of Medical Sciences. The inclusion criteria consisted of no use of anti-microbial mouthwashes during the past month and no use of anti-fungal agents, antihistamines and corticosteroids, and a caries index $>4$. The samples were collected after briefing the children's parents and obtaining informed written consent forms. The samples were immediately cultured on Sabouraud dextrose agar plates (Scharlau-Merck, Germany) in association with chloramphenicol. After fungal growth, a part of the colony was transferred to the CHROMagar culture medium (CHROMagar Candida, Paris, France). C. albicans species was confirmed by the color produced on the CHROMagar medium and formation of a germ tube in serum and production of vesicles in the cornmeal agar median (Himedia Laboratories, Ltd, Mumbai, India) plus $1 \%$ Tween 80 . Then, a suspension of 48 -hour yeast colonies was prepared in the Sabouraud Dextrose Agar with Chloramphenicol medium with the use of physiologic serum. Then, a standard $0.5 \mathrm{McF}$ arland concentration was prepared using the well technique with the disk placemat method. Microdilutions of yeasts were prepared at $5 \times 10^{2}-2.5 \times 10^{3}$ in each $\mathrm{mL}$ with the use of RPMI medium (Sigma-Aldrich, Germany).

\subsection{Preparation of aqueous and ethanolic leaf extract of $L$. citriodora}

L. citrodora leaves were collected from the Research Garden of Babol University of Medical Sciences in May 2015, rinsed, dried at room temperature for 27 hours, and milled. To prepare the aqueous extract, $30 \mathrm{~g}$ of the dry powder of the leaves were mixed with $100 \mathrm{~mL}$ of water at $70-80{ }^{\circ} \mathrm{C}$, which had already been boiled, and stored at room temperature for 24 hours. The resultant extract was filtered through Whatman filter papers (Whatman No. 1) and placed in an oven at $40-50{ }^{\circ} \mathrm{C}$ for drying. The dry weight of the material was determined. This extract was considered the aqueous extract of $L$. citriodora. To prepare the ethanolic extract, $75 \mathrm{~g}$ of the dry material and 250 $\mathrm{mL}$ of $95 \%$ dehydrated ethanol were poured in a beaker, and, after 48 hours, the resultant solution was filtered through No. 1 Whatman paper filters and dried in a vacuum machine. The dry ethanolic extract was weighed. This extract was considered the dry ethanolic extract.

\subsection{Evaluation of the antifungal activity with the use of disk diffusion technique}

Sterile paper disks were immersed in the final concentrations of $156-2500 \mu \mathrm{g} / \mathrm{mL}$ of the aqueous (dissolved in water) and ethanolic (dissolved in dimethyl sulfoxide, DMSO) extracts, $4-64 \mu \mathrm{g} / \mathrm{mL}$ of fluconazole (dissolved in water) and $8-128 \mu \mathrm{g} / \mathrm{mL}$ of nystatin (dissolved in dimethyl sulfoxide, DMSO) and then dried. The suspension prepared from $C$. albicans in sterile physiologic serum was spread on a plate containing Sc medium using a sterile swab. Five disks containing different concentrations of the aqueous and ethanolic extracts of L. citriodora, nystatin and fluconazole were placed separately in each plate. The disks were placed at a distance of $15 \mathrm{~mm}$ from the plate margin and $24 \mathrm{~mm}$ from the center of the adjacent disk. A disk with no preparation and a disk with $0.2 \%$ DMSO were considered as negative controls. Then, the diameter of the transparent halo around each disk was measured. Halo diameters $\geq 2 \mathrm{~mm}$ indicated antifungal activity (14). All of the plates were prepared in duplicate and incubated at $37^{\circ} \mathrm{C}$ for 48 hours.

\subsection{Evaluation of the antifungal activity using the well technique}

The suspension prepared from C. albicans in sterile physiologic serum was inoculated on a plate containing Sabouraud dextrose agar culture medium along with chloramphenicol with the use of a sterile swab. After two 
hours, cavities measuring $6 \mathrm{~mm}$ in diameter were prepared in it. Different concentrations of the aqueous extract (dissolved in water), ethanolic extract (dissolved in DMSO), fluconazole (dissolved in water) and nystatin (dissolved in DMSO) were added to the wells. All of the plates were prepared in duplicate and incubated at $37{ }^{\circ} \mathrm{C}$ for 48 hours.

\subsection{Microdilution to determine the minimum inhibitory concentration (MIC)}

MIC was determined with the use of CLSI-M27-A3 (Clinical and Laboratory Standard Institute) standard technique to determine the inhibitory and lethal effect of the medication (15). Nine series of different concentrations of the extract were prepared in duplicate at the final concentrations of $19-5000 \mu \mathrm{g} / \mathrm{mL}, 0.25-64 \mu \mathrm{g} / \mathrm{mL}$ of fluconazole, $0.5-128 \mu \mathrm{g} / \mathrm{mL}$ nystatin in a total volume of $100 \mu \mathrm{L}$ in sterile $96-w e l l$ ELISA plates with flat bottoms, containing $100 \mu \mathrm{L}$ of RPMI. Then, the fungal suspension at concentrations of $5 \times 10^{2}-2.5 \times 10^{3}$ yeast cells $/ \mathrm{mL}$ was added to the plates at a volume of $100 \mu \mathrm{L}$. All of the plates were prepared in duplicate and incubated at $35{ }^{\circ} \mathrm{C}$ for 48 hours. Positive and negative controls and DMSO solution also were considered.

\subsection{Statistical analysis}

The data were analyzed using Tukey's post hoc and One-Way ANOVA tests using SPSS 18 software, and they were expressed as the mean \pm the standard error of the mean (SEM). The data obtained from the ethanolic and aqueous extracts of lemon verbena were compared with the findings of the control group fluconazole and nystatin and $\mathrm{p}<$ 0.05 was considered statistically significant.

\section{Results}

In the present in vitro study, the samples were collected from 22 volunteers as follows: 10 subjects in the 4-6 age group and 12 in the 7-12 age group, with mean DMFT score of 5.5 and 8.6 respectively. Of the 22 samples cultured, two were not $C$. albicans samples, and no fungal growth was detected in five samples. The presence of green colonies in 15 CHROMagar culture media indicated the growth of C. albicans (Figure 1). In addition, all of these microorganisms produced germ tubes and vesicles (chlamydoconidium) in the cornmeal agar along with $1 \%$ Tween 80 in 13 plates (Figure 2). In this study, the anti-fungal activities of different concentrations of aqueous and ethanolic extracts of $L$. citiodora leaves against $C$. albicans were evaluated with the use of disk diffusion, well, and microdilution techniques in comparison to nystatin and fluconazole.

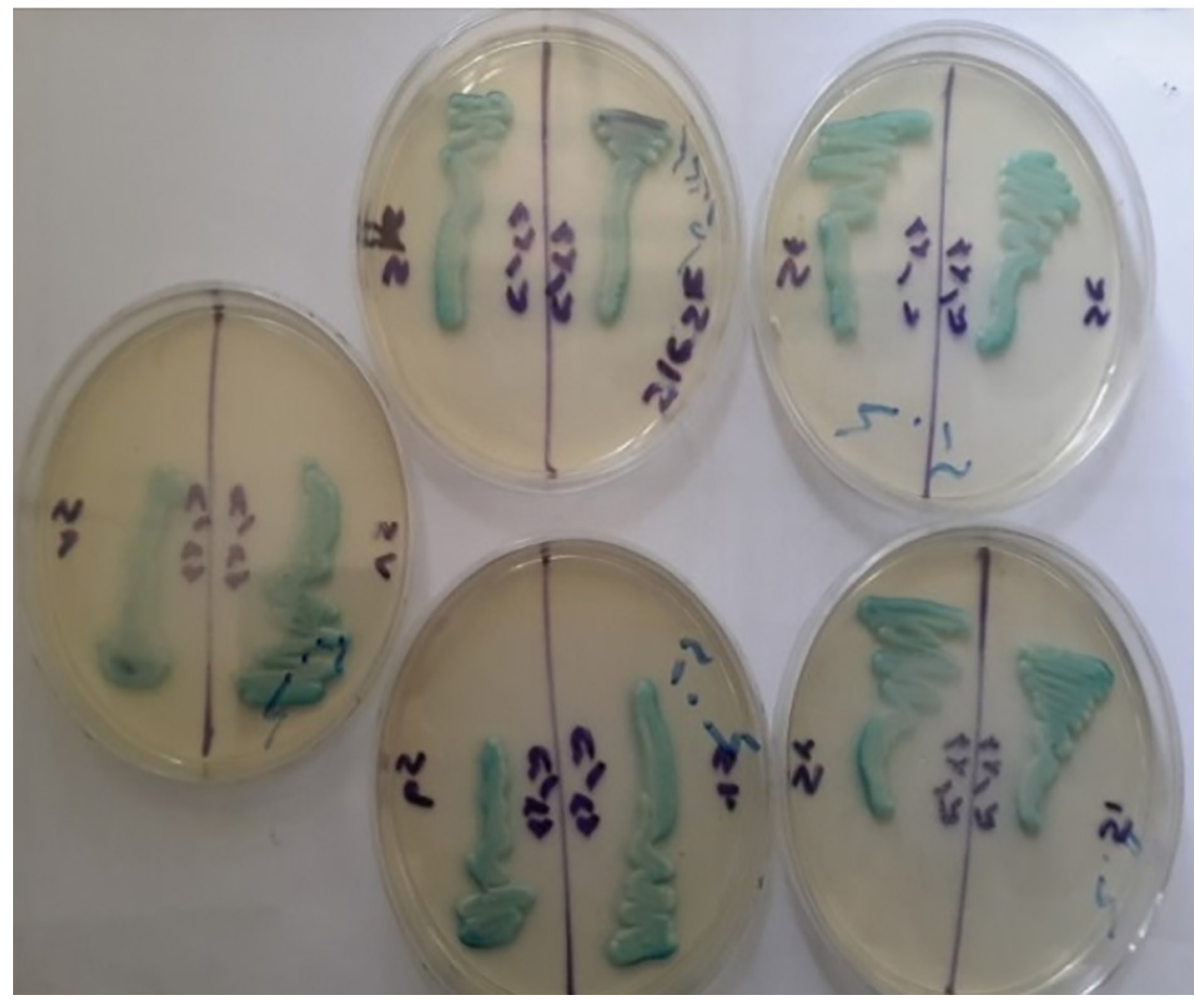

Figure 1. CHROMagar culture media indicating the growth of C. albicans 
In the well and disk diffusion techniques, small growth inhibitory halos were observed around a number of clinically-isolated stains; however, no inhibitory halos were observed around the standard strains. In addition, the aqueous extract exhibited no inhibitory halos in the disk diffusion and well techniques. The diameters of growth inhibitory halos with nystatin-containing disks (with the minimum concentration of $8 \mu \mathrm{g} / \mathrm{mL}$ around the isolated and standard stains) were $0.53 \pm 0.53$ and 0 ; the maximum diameters of growth inhibitory halos at a concentration of 128 $\mu \mathrm{g} / \mathrm{mL}$ around clinically-isolated and standard stains increased to $16.13 \pm 0.44$ and 17 in a dose-dependent manner. In addition, the growth inhibitory halos in the same order in the well technique with the minimum nystatin concentration were $0.535 \pm 0.55$ and 0 , and, with the maximum concentration, they were $17.8 \pm 0.59$ and 17 . The growth inhibitory halo diameters for $4 \mu \mathrm{g} / \mathrm{mL}$ of fluconazole with the clinically isolated and standard strains in the disk diffusion technique were $0.57 \pm 0.55$ and 0 , and in the well technique they were 0 and 0 . With the maximum concentration $(64 \mu \mathrm{g} / \mathrm{mL})$, the diameters were $15.53 \pm 1.28$ and 17 , and $17.33 \pm 0.36$ and 18 , respectively. MICs are presented in Table 1 . The MIC results showed a higher inhibitory effect of ethanolic extract of L. citriodora than its aqueous extract. In addition, the standard strain exhibited higher sensitivity than the clinically isolated C. albicans strains at the concentrations evaluated. Although no growth inhibitory halos were detected in the disks and wells containing the aqueous extract, in the MIC technique, the growth inhibitions for the clinical and standard strains were $833 \pm 78.5$ and $2500 \mu \mathrm{g} / \mathrm{mL}$, respectively. The MIC of the ethanolic extract was $833 \pm 78.5$ and $625 \mu \mathrm{g} / \mathrm{mL}$ for the isolated and standard strains, respectively, indicating higher inhibitory potential for the ethanolic extract than the aqueous extract $(\mathrm{p}=0)$. In addition, the MIC of nystatin for clinical and standard strains was $10.13 \pm 1.91$ and 4 , respectively, with $1.97 \pm 0.25$ and $1 \mu \mathrm{g} / \mathrm{mL}$, respectively for fluconazole. Although the MIC of the ethanolic extract of $L$. citriodora was higher than those of nystatin and fluconazole $(\mathrm{p}=0)$, this extract exhibited anti-fungal activity.

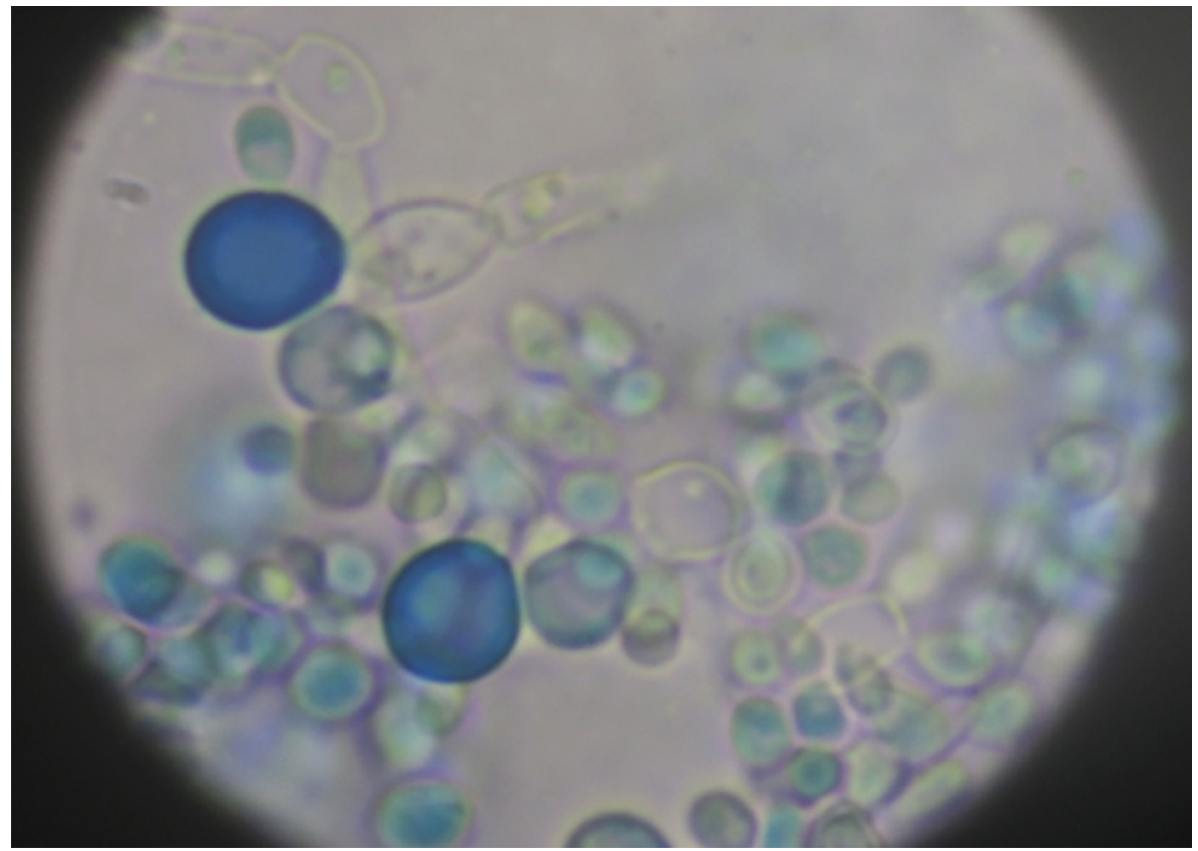

Figure 2. Chlamydoconidium in the cornmeal agar

Table 1. Means and standard deviation of minimal inhibitory concentration (MIC) of Aqueous and Ethanolic extracts of Lippia citriodora, Nystatin and Fluconazole against Candida albicans

\begin{tabular}{|l|l|l|l|}
\hline \multirow{2}{*}{ Extracts } & Range $(\mu \mathrm{g} / \mathrm{ml})$ & $\mathrm{MIC}(\mu \mathrm{g} / \mathrm{ml})$ \\
\cline { 3 - 4 } & & Candida albicans (Clinical isolate, No. 15) & Candida albicans $(\mathrm{PTCC} 5027)$ \\
\hline Aqueous & $19-5000$ & $4156 \pm 67.4$ & 2500 \\
\hline Ethanolic & $19-5000$ & $833 \pm 78.5$ & 625 \\
\hline Nystatin & $0.5-128$ & $10.13 \pm 1.91$ & 4 \\
\hline Fluconazole & $0.25-64$ & $1.97 \pm 0.25$ & 1 \\
\hline
\end{tabular}




\section{Discussion}

The present study evaluated the anti-fungal effects of aqueous and ethanolic extracts of $L$. citriodora leaves on $C$. albicans. The results showed that 15 colonies of these fungal species were green in color in the CHROMagar culture medium, indicating the presence of C. albicans. In addition, all of these colonies produced germ tubes, and 13 strains produced vesicles (Chlamydoconidium) in the cornmeal agar medium. A previous study showed the antioxidative activity of leaf extract of L. citriodora. In addition, the anti-microbial and anti-fungal properties of $L$. citriodora leaves have been attributed to aromatic and polyphenolic compounds in the leaves (16-18). In the present study, the effects of aqueous and ethanolic extracts of $L$. citriodora leaves were evaluated using the disk diffusion, well diffusion, and MIC techniques. In the well and disk diffusion techniques, limited growth inhibition halos were produced around some clinical isolates at different concentrations of the ethanolic extract; however, no growth inhibitory halos were observed with any concentrations of the aqueous extract. Absence of growth inhibitory halos around disks containing the extract might be attributed to the fact that, in the present study, a lower concentration of the extract was used compared to previous studies. In addition, since the effective material in the well and disk diffusion technique gradually diffuses into the environment and affects the margins of the growing colonies, the fungal species in question had the opportunity to make use of its defensive mechanisms to counteract the material's toxicity through a proper technique; however, in the micro-dilution technique, mixing of the extract with the culture medium resulted in the presence of the effective material in all the areas of the environment. Therefore, it can be expected that the threshold of response of each fungal species to the anti-fungal agent will be different (19). The MICs of ethanolic extract, in the present study, on clinically isolated and standard strains were $833 \pm 78.5$ and 625 $\mu \mathrm{g} / \mathrm{mL}$, respectively, which were much lower than those in a 2005 study by Oskay, which showed that the MIC of methanolic extract of L. citriodora leaves on C. albicans was $6 \mathrm{mg} / \mathrm{mL}(20)$. In the present study, inhibition occurred at a lower concentration than that in the study by Oskay, which might be attributed to higher levels of polyphenols and aromatic compounds in the extract $(13,17)$. In the present study, the MICs of the aqueous extracts with clinically isolated and standard strains were $4156 \pm 67.4$ and $2500 \mu \mathrm{g} / \mathrm{mL}$ respectively, indicating a lower inhibitory potential of the aqueous extract than the ethanolic extract. In a 2013 study by Koohsari, the antibacterial effects of aqueous and ethanolic extracts of L. citriodora were evaluated at concentrations of $125-1000 \mathrm{mg} / \mathrm{mL}$ on nine pathogenic species with the use of disk diffusion and well techniques. The results showed that the ethanolic extract exhibited an antibacterial effect; however, the aqueous extract had no inhibitory effect on the pathogenic species. The results showed that E. faecalis, S. epidermidis, and S. aureus were the most sensitive bacteria among gram-positive bacteria and that $Y$. enterocolitica was the most resistant gram-negative bacterial species (14). Most plant extracts have anti-microbial properties and consist of saturated organic or aromatic compounds. In most cases, ethanolic or methanolic solvents are used for their initial extraction and, typically in the majority of studies, the use of water is avoided for extraction of plant derivatives (21). Since the presence of phenolic components in plant extracts is one of the main reasons for their anti-microbial effects, it is possible that the presence of very small amounts of phenolic compounds in the aqueous extract was the reason for the low anti-microbial effect of this extract (17). Lozada, in a 2012 study, evaluated the effect of the essential oils of L. citriodora and L. origanoid on growth inhibition of Moniliophthora roreri, and the results showed complete inhibition of fungal growth at concentrations of $600-1000 \mu \mathrm{g} / \mathrm{mL}(22)$. Observations in relation to the essential oils of L. citriodora showed its high anti-bacterial activity against $H$. pylori (23). A 2010 study by Ramzi showed that $L$. citriodora extract has an inhibitory effect on gram-positive bacteria, but it had no effect on Candida maltosa (24). In 2012, Ansari conducted a study with $1 / 2,1 / 4,1 / 8$, and $1 / 16$ concentrations of $100 \mu 1$ of $L$. citriodora extract using disk diffusion technique to determine MIC against $S$. aureus strain resistant to methicillin. The results showed that the inhibitory effect increased with an increase in the concentration of the extract up to $55 \mu \mathrm{g} / \mathrm{mL}$. In addition, the MIC was determined at $15 \mu \mathrm{g} / \mathrm{mL}$, and the results showed a high anti-microbial activity against methicillin-resistant $S$. aureus despite very low toxicity against cells (25). The anti-bacterial activity of the extract might be attributed to the presence of alkaloids, flavonoids, and tannin in its chemical structure (23). Tatsadjieu evaluated the antifungal activity of Lippia rugosa leaves and showed that geraniol, neral, and geranial in the extract were the agents responsible for the antifungal activity against Aspergillus flavus (26). A study in 2009 by Royaro showed that the extract of L. citriodora leaves exhibited the highest anti-fungal activity at inhibitory concentrations of 99.21 and $65.5 \mu \mathrm{g} / \mathrm{mL}$ against $\mathrm{C}$. krusei and Aspergillus fumigatus, respectively (22). A study in 2012 by Lozada showed that the essential oils of $L$. citriodora and L. origanoid resulted in $90 \%$ inhibition of fungal growth at a concentration of $200 \mu \mathrm{g} / \mathrm{mL}$; however, $100 \%$ inhibition was achieved at concentrations in the range of $800-1000 \mu \mathrm{g} / \mathrm{mL}$ (27). A study in 2007 by Oliviera on the antibacterial activity of $L$. origanoid with the use of drop diffusion technique showed its inhibitory effects on gram-positive microorganisms, including S. aureus and C. albicans (28). A study in 1994 by Villon and Chaumont showed the antifungal activity of Lippia multiflora and Lippia chevalieri extracts against Aspergillus flavus. They reported that trepenoids, especially citral and geraniol that are present in extract of L. citriodora, were responsible 
for the anti-fungal activity (29). Other anti-fungal agents are beta-caryophyllene and beta-caryophyllene oxide that belong to cisquiterpens and are found in the plant extracts of Lippia rehmanii and Lippia citriodora (30). Despite the complications reported in previous studies in relation to other antifungal agents, no side effects have been reported after the use of leaf extract of L. citriodora; on the contrary, its positive protective effects on the general health have been shown $(7,10,11,16,30,31)$.

\section{Conclusions}

The results of the present study showed that the aqueous extract, and particularly the ethanolic extract, of the leaves of $L$. citriodora has activity against $C$. albicans, which might be attributed to the higher content of aromatic agents, including essences and polyphenols, in the ethanolic extract compared to the aqueous extract. Use of this extract can be suggested to volunteers, after evaluating them, as an agent against $C$. albicans.

\section{Acknowledgments:}

This study was based on post-graduate research conducted by Faranak Shafiee. The authors appreciated the financial support of the Research Center of Babol University of Medical Sciences (grant number 9339423). We also thank Mrs. Maryamosadat Shafiee for providing some practical works.

\section{Conflict of Interest:}

There is no conflict of interest to be declared.

Authors' contributions:

All authors contributed to this project and article equally. All authors read and approved the final manuscript.

\section{References:}

1) Neville BW, Damm OD, Allen CM, Bouquot JE. Oral and Maxillofacial Pathology. 3th ed. Elsevier Sunders; 2009, ch6:213-8.

2) Williams D, Lewis M. Pathogenesis and treatment of oral candidosis. J Oral Microbial. 2011; 3(10): 34027. doi: $10.3402 /$ jom.v3i0.5771.

3) Raja M, Hannan A, Ali K. Association of oral candida carriage with dental caries in children. Caries Res. 2010; 44(3): 272-6. doi: 10.1159/000314675, PMID: 20516688.

4) Silva DS, Cavalho FC, Hebling J. Presence of mutants streptococci and candida spp. In dental plaque/dentin of carious teeth and early child hood caries. Caries Res. 2006; 51(11): 1024-8. doi: 10.1016/j.archoralbio.2006.06.001, PMID: 16890907.

5) Pina-Vaz C, Rodrigues AG, Pinto E, Costa-de-oliveira S, Tavares C, Salgueiro L, et al. Antifungal activity of Thymus oils and their major compunds. J Eur Acad Dermatol. 2004; 18(1): 73-8. doi: 10.1111/j.14683083.2004.00886.x, PMID: 14678536.

6) Zarei Mahmoudabadi A, Antifungal drugs. First ed. Ahwaz. Medical Sciences University of Ahwaz Pub. 2002. Persian.

7) Abderrahim F, Estrella S, Susin C, Arribas SM, González MC, Condezo-Hoyos L. The antioxidant activity and stability of lemon verbena infusion. J Med Food. 2011; 14(5): 517-27. doi: 10.1089/jmf.2010.0102, PMID:21434775.

8) Mothana RAA, Abdo SA, Hasson S, Althawab FM, Alaghbari SA, Lindequist U. Antimicrobial, antioxidant and cytotoxic activities and phytochemical screening of some Yemeni medicinal plants. Evid Based Complement Alternat Med. 2010; 7(3): 323-30. doi: 10.1093/ecam/nen004, PMID: 18955315. PMCID: PMC2887327

9) Chavallier A. The Encyclopedia of medicinal plants, Dorling Kinderseley. London. 1996; p 227.

10) Santos G, fernandes F. Composition of the essential oils from flowers and leaves of vervain. J Essent Oil Res. 2005; 17(1): 73-7. doi: 10.1080/10412905.2005.9698835.

11) Pastorelli G, Rossi R, Corino C. Influence of lippia citriodora verbacoside on growth performance, antioxidant status, and serum immunoglobulins content in piglets. Czech J Anim Sci. 2012; (7): 312-22.

12) Valenta o P, Fernandes E, Carvalho F, Andrade PB, Seabra RM, de Lourdes Basto M. Studies on the antioxidant activity of Lippia citriodora infusion: scavenging effect on superoxide radical, hydroxyl radical and hypochlorous acid. Biol Pharm Bull. 2002; 25: 1324-7. doi: 10.1248/bpb.25.1324.

13) Cushnie TPT, Lamb AJ. Antimicrobial activity of flavonoids. Int J antimicrobial agents. 2005; 26(5): $343-$ 56. doi: 10.1093/ecam/nen004, PMID: 18955315. 
14) Koohsari H, Ghaemi EA, sheshpoli M, Sadegh A. Evaluation of antibacterial activity of Lemon verbena leaves. Ann Bio Res. 2013; 4(10): 52-5.

15) Clinical And Laboratory Standatds Institutes. Refrence Method for Broth Dilution Antifungal Susceptibility Testing of Yeasts; Approved Standard-Third Edition. M27-A3. 2008; 28(14).

16) Valentao P, Fernandes E, Carvalho H. Studies on the antioxidant activity of lippiacitriodora infusion: scavenging effects on superoxide radical, hydroxyl radical and hypochlorus acid. Biol Pharm Bull. 2002; 25(10): 1324-1327. doi: 10.1248/bpb.25.1320, PMID: 12392087.

17) Choupani M, Arabsha S, Delouee I, Alami M. Antioxidant Properties of Various Solvent Extracts of Lemon Verbena (LippiaCitriodora) Leaves. Int j AdvanBiol and Biomed Res. 2014; 2(4): 1340-6.

18) Carnat A, Carnat AP, Chavignon O, Heitz A, Wylde R, Lamaison JL. Luteolin 7-diglucuronid, the major flavonoid compound from Aloysiatriphylla and Verbena officinalis. Planta Med. 1995; 61(5): 490-1. doi: 10.1055/s-2006-958152, PMID: 7480218.

19) Marzuk Z, Marzuk B, chraief I, Boukef K. Analysis of Tunisian Menthapulegium L. oils from Monastir. SIPAM. 2006.

20) Oskay M, Usame Tamer A, Gungor AY, Sari D, Aktas K. Antimicrobial Activity of the Leaves of Lippia triphylla O. Kuntze (Verbenaceae) Against on Bacteria and Yeasts. J Biol Scien J. 2005; 5(5): 620-2. doi: $10.3923 /$ jbs.2005.620.622.

21) Cowan MM. Plant products as antimicrobial agents. Clinical Microbiol Rev. 1999; 12: 564-82. PMID: 10515903, PMCID: PMC88925.

22) Lozada BS, Viviana Herrera L, Perea JA, Stanshenko E, Escobar P. In vitro effect of essential oils of three Lippia species on Moniliophthora roreri (Cif. and Par.) causative agent of moniliasis of cocoa. Acta Agron. 2012; 61(2): 94-102.

23) Ohno T, Kita M, Yamaoka Y, Imamura S, Yamamoto T, Mitsufuji S, et al. Antimicrobial activity of essential oils against Helicobacter pylori. Helicobacter. 2003; 8: 207-15. doi: 10.1046/j.15235378.2003.00146.x, PMID: 12752733.

24) Ramzi AA, Mothana Salah AA, AbdoSidgi H, Faisal MN, AlthawabSama AZ. Antimicrobial, Antioxidant and Cytotoxic Activities and phytochemical screening of some Yemeni medicinal plants. Act Screen Yemeni Med Plant. 2010; 7(3): 323-30.

25) Ansari M, Larijani K, Tehrani MS. Antibacterial activity of Lippa citriodora herb essence against MRSA Staphylococcus aureaus. AJMR. 2012; 6: 16-9.

26) Tatsadjieu NL, Jazet Dongmo PM, Nagssoum MB, Etoac FX, Mbofung CMF. Investigations on the essential oil of Lippiarugosa from Cameroon for its potential use as antifungal agent against Aspergillus flavus ex Fries. Food Control. 2009; 20(2): 161-6. doi: 10.1016/j.foodcont.2008.03.008.

27) Correa-Royero J, Tangarife V, Duran C. Invitro antifungal activity and cytotoxic effect of essential oils and extracts of medicinal and aromatic plants against Candida Krusei and Aspergillus fumigatus. Braz J Pharm. 2009; 20(5): 734-41.

28) Oliveira DR, Leitao GG, Bizzo HR, Lopes D, Alviano DS, Alviano CS, Leitao SG. Chemical and Antimicrobial analyses of essential oil of Lippia origanoides H.B.K. Food Chemistry. 2007; 101: 236-240, doi: 10.1016/j.foodchem.2006.01.022.

29) Viollon C, Chaumont JP. Antifungal properties of essential oils and their main components upon Cryptococcus neoformans. Mycopathologia. 1994; 128: 151-3. PMID: 7739729.

30) Pascual ME, Slowing K, Carretero E, Sanchez D, Mata D, Villar A. Lippia: traditional uses, chemistry and pharmacology: a review. J Ethnopharmacol. 2001; 76: 201-14. PMID: 11448540.

31) Santoro A, Bianco G, Picerno P, Aquino RP, Autore G, Marzocco S, et al. Verminoside- and Verbacosideinduced genotoxicity on human lymphocytes: Involvment of PARP1 and P53 proteins. Toxicolo let. 2008; 178(2): 71-6. doi: 10.1016/j.toxlet 2008.02.006, PMID: 18395372. 